\title{
An improved approach investigating epithelial ion transport in scleractinian corals
}

Taubner I., Böhm F., Eisenhauer A., Tambutté E., Tambutté S., Moldzio S., Bleich M.

Preprint

Limnology and Oceanography - Methods

available online $7^{\text {th }}$ June 2017

Published in Limnology and Oceanography - Methods, 15, 9, 753-765 


\section{An improved approach investigating epithelial ion transport in}

\section{scleractinian corals}

Isabelle Taubner1,2; Florian Böhm²; Anton Eisenhauer2; Eric Tambutté3; Sylvie

Tambutté3; Stephan Moldzio ${ }^{4}$ and Markus Bleich ${ }^{1}$

\section{Addresses}

${ }^{1}$ Christian-Albrechts-Universität, Institute of Physiology, Kiel, Germany

${ }^{2}$ GEOMAR Helmholtz Centre for Ocean Research Kiel, Marine Biogeochemistry Division, Kiel, Germany

${ }^{3}$ Centre Scientifique de Monaco, Marine Biology Department, Monaco

${ }^{4}$ Green Corals, Braunschweig, Germany

\section{Running head}

Coral epithelial transport measurement

\section{Keywords}

Stylophora pistillata, electrophysiology, Ussing chamber, ion selectivity, paracellular transport, ion transport

\section{Corresponding authors}

Isabelle Taubner and Markus Bleich

Institute of Physiology

Christian-Albrechts-Universität

Hermann-Rodewald-Str. 5

24118 Kiel, Germany

itaubner@geomar.de

m.bleich@physiologie.uni-kiel.de 


\section{Abstract}

Coral epithelia control ion fluxes to the calcification site influencing biomineralisation and proxy incorporation. However, data on in vivo characteristics of coral tissue such as permeability, selectivity and active ion transport are scarce but important for calcification and proxy modelling.

To investigate ion permeability and ion fluxes across coral tissues in vivo, we developed an electrophysiological approach for the assessment of active and passive epithelial transport properties. Growing Stylophora pistillata corals in a thin layer over permeable filters allowed ion exchange at the site of skeleton formation for reproducible measurements of electrophysiological properties of coral tissues in a modified Ussing chamber. Compared to former applications, electrical measurements on these coral filter units were dominated by tissue characteristics with minimal influence of skeleton or physical stress.

Coral tissues were cation selective. Their overall high electrical resistance characterized them as tight epithelia indicating low paracellular permeability for passive ion diffusion. This includes ions relevant for calcification. A small short-circuit current indicates active charge transport across the entire coral tissue.

The present approach is applicable to corals laterally overgrowing substrates. It allows the electrophysiological characterization of coral tissue in vivo in response to environmental conditions. This will improve our knowledge on transepithelial transport relevant for biomineralisation in corals.

\section{Introduction}

Coral skeletons are successfully used as climate proxy recorders, in spite of strong vital effects, which have been connected to biologically controlled ion transport and fast 
precipitation rates. Scleractinian corals are among the fastest calcifiers in the world's oceans (Cohen and McConnaughey 2003), the average net calcification rate of corals ranging from 0.1 to $3 \mu \mathrm{mol} \mathrm{CaCO}_{3} \mathrm{~cm}^{-2} \mathrm{~h}^{-1}$ (Allemand et al. 2004; Lough 2008). To support these high calcification rates corals have to maintain a high ion flux from seawater through their tissues to the site of calcification where the aragonitic skeleton is formed. Coral tissues must meet certain requirements to support and control high ion fluxes and to be able to provide an environment where precipitation of $\mathrm{CaCO}_{3}$ occurs. Ion fluxes through tissues can occur 1) through active transcellular transport, which is strictly controlled by membrane proteins (e.g. ion channels, pumps and carriers) and 2) through paracellular pathways i.e. between the cells where the properties of intercellular junctions define ion permeability and selectivity of the tissues and the degree of isolation of the site of calcification. Several ultrastructural studies carried out on corals clearly show that septate junctions - characterised by their ladder-like arrangement of transverse septa - are located at the apical part between the calicoblastic cells of the coral's aboral ectoderm facing the skeleton (Clode and Marshall 2002; Tambutté et al. 2007; Ganot et al. 2014).

Passive permeability properties of the tissues together with regulation of active transport have a strong impact on models explaining calcification and trace element incorporation into coral skeletons. Several models have described the site of calcification as a leaky system largely open to ion exchange with seawater (Adkins et al. 2003; Cohen and McConnaughey 2003; Nakamura et al. 2013) while other models describe it as a closed system strictly controlled by the coral tissue (Tambutte et al. 1996; Böhm et al. 2006; Hohn and Merico 2015). These models are mostly based on indirect indicators of tissue permeability $\left(\delta^{13} \mathrm{C},{ }^{45} \mathrm{Ca}, \delta^{44 / 40} \mathrm{Ca}\right.$, internal $\mathrm{pH}$ and $\mathrm{Ca}$ concentration). Only a few direct measurements of tissue permeability have been 
carried out on the oral epithelia and not on the entire tissue of corals (Wright and Marshall 1991; Bénazet-Tambutté et al. 1996). Coral tissue consists of oral and aboral layers, which are further subdivided into an endodermal, and an ectodermal cell layer. The two oral layers form coral polyps and are in direct contact with seawater, while the aboral layers are tightly attached to the skeleton. The aboral ectoderm (calicoderm) is responsible for calcification. Results from these two studies showed that ions diffuse easily through the leaky oral epithelia. As these experiments were performed on polyp tentacles, they did not consider the aboral epithelia, which include the calicoderm responsible for skeleton formation. So far, only one study indirectly measured the permeability of the entire coral tissue still attached to its skeleton (Tambutté et al. 2012) applying the Ussing chamber technique.

Originally developed as an experimental approach to study ion transport through biological tissues (Ussing and Zerhan 1950; Ussing 1953; Ussing et al. 1974) the technique provides side specific access of experimental solutions to a sheet of polarized tissue for electrical measurements. This technique can be used to characterize transepithelial transport of ions and to determine the permeability properties of epithelia. In addition, measurements of calcium transport were established, e.g. in mouse kidney tubules (Bleich et al. 2012), sea anemones and corals (Wright and Marshall 1991; Bénazet-Tambutté et al. 1996). The use of pharmacological tools allows the functional analysis of prototypic transport pathways (Greger and Schlatter 1981; Lohrmann et al. 1995; Shan et al. 2009) and the differentiation between trans- and paracellular pathways. In addition, the chamber allows the determination of tracer fluxes across the epithelium (e.g. ${ }^{45} \mathrm{Ca},{ }^{14} \mathrm{C}$; Wright and Marshall 1991; Bénazet-Tambutté et al. 1996). The Ussing chamber consists of two half-chambers perfused with experimental solutions, which are separated by the biological tissue under investigation. 
Since epithelia are polar in nature ion flux by electrogenic transcellular ion transport is directional and causes an electrical current across the tissue and a corresponding voltage difference (transepithelial potential, $\mathrm{V}_{\text {te }}$ ) between the two half-chambers (Fig. 1a). The electrical resistance $\left(R_{t e}\right)$ is calculated from voltage deflections across the epithelium $\left(\Delta \mathrm{V}_{\text {te }}\right)$ caused by the injection of short current pulses $(\Delta \mathrm{I})$. It is a measure for tightness of the tissue. By Ohm's law, an equivalent short circuit current $\left(\mathrm{I}_{\mathrm{sc}}\right)$ can be calculated which represents the active electrogenic transepithelial charge movement. Passive ion permeability and selectivity can be deduced from diffusion voltages $\left(V_{D}\right)$ at a given ion gradient (e.g. for $\mathrm{Na}^{+}$) between the two half-chambers (Fig. 1b) giving insights into the paracellular properties of the tissue in the absence of active transcellular ion transport.

Although critical for calcification and proxy modelling, very little information is available on the in vivo characteristics of coral tissue. One of the reasons is that access to the site of calcification is difficult since it is at the interface between the massive aragonitic skeleton and a complex tissue made of four epithelia in series (Fig. 1c). The objectives of this study are to establish a method for investigating coral tissue properties such as permeability, ion selectivity and active ion transport in vivo. This method can be applied to better understand transepithelial transport relevant for biomineralisation in corals. We developed a method for applying the Ussing chamber technique to coral microcolonies growing on permeable filter supports. Our set-up allows access from both, skeletal and oral side, with an intact and natural anatomy of calcifying coral tissue. Previously described preparations do not fulfil these requirements (Domart-Coulon et al. 2004; Mass et al. 2012).

We cultured coral tissue on a planar filter area with minimal skeleton mass and simple geometry. This preparation was mounted in an Ussing chamber and allowed to obtain 
electrophysiological data on coral tissues. It was possible to control and modify the composition of solutions on both sides, as well as environmental parameters such as light and temperature.

\section{Materials and procedures}

\section{Coral culture}

Colonies of the tropical calcifying coral Stylophora pistillata (Coelenterata: Anthozoa: Hexacorallia: Scleractinia) were maintained in artificial seawater under a controlled day:night cycle. All colonies originate from one mother colony of Stylophora pistillata, which was provided by Green Corals, Braunschweig, Germany. Culturing and preparation of corals were carried out at the GEOMAR Helmholtz Centre for Ocean Research Kiel, Kiel, Germany. A 600 L closed-recirculation system specifically designed for reef building, zooxanthellate warm water corals was set up by Green Corals, Braunschweig, Germany. The setup comprised a main reef-tank, a culture tank for growing and preparing the corals for the experiments and a cleaning unit (with three compartments, the first filled with live rock, the second with a protein skimmer, and the third with a return pump and sensing electrodes $(\mathrm{pH}, \mathrm{T}$, water level) connected with an IKS-aquarium computer). The main reef tank was inhabited by a community of stony and soft corals, live rock and accompanying reef fauna and flora, including fish, snails and hermit crabs. The animals were fed six times a week with frozen Artemia (Golden Gate), Cyclops (Vivantis), fish eggs (Petman) and spirulina flakes (JBL, Germany). After defrosting, food was thoroughly rinsed with freshwater to avoid an additional phosphate $\left(\mathrm{PO}_{4}{ }^{3-}\right)$ import into the closed-recirculation system. Corals were kept in artificial culturing seawater (CSW) made from commercial sea salt ("Pro Reef" sea salt; Tropic Marin ${ }^{\circledR}$, Germany) at a salinity of 35psu. A $10 \%$ water exchange was conducted 
every six weeks. Decrease of calcium concentration $\left(\left[\mathrm{Ca}^{2+}\right]\right)$ and carbonate alkalinity due to calcification in the aquarium was compensated by a calcium reactor filled with limestone which was continuously dissolved by $\mathrm{CO}_{2}$ at a $\mathrm{pH}$ value $<6$. Additionally $\mathrm{CaCl}_{2}$, $\mathrm{NaHCO}_{3}$, trace elements, and $\mathrm{NaCl}$-free salt solutions were added according to the "Balling light method" to maintain stable water parameters, which is crucial for keeping highly sensitive small polyped stony corals. The concentrations of $\mathrm{Ca}^{2+}$ and total alkalinity were kept at $420 \mathrm{mg} \mathrm{L}^{-1}$ and $2400 \mathrm{mEq} \mathrm{L}^{-1}$, respectively. Bioavailable nitrogen was supplied as $\mathrm{NH}_{4} \mathrm{Cl}\left(6.7 \mathrm{mmol} \mathrm{d}^{-1}\right)$. Seawater was circulated in a closed circuit at a temperature of $26 \pm 1^{\circ} \mathrm{C}$. Due to photosynthesis and respiration, the seawater $\mathrm{pH}$ ranged from 8.2 during the day to 7.9 in the night. The lighting in the main reef tank and the culture tank was provided by 8 and 6, respectively, 54W T5 fluorescent lamps, with three different spectral compositions ("Aqua Blue Special”, “Blue Plus”, “Coral Plus”; ATI Aquaristik, Germany). The day-night cycle was programmed on a $12 \mathrm{~h} \mathrm{L/D} \mathrm{cycle}$ whereas each phase shift was introduced by one hour of blue light only. At the surface of the experimental corals photosynthetically active radiation was $237 \pm 55 \mu$ mol photons $\mathrm{m}^{-2} \mathrm{~s}^{-1}$ (mean $\pm 1 \mathrm{sd}$ ) recorded using a hyperspectral quantum sensor (RAMSES, TriOS Science). Corals in the culturing aquarium were fed up to six times a week with a powdered plankton substitute and a combination of soluble amino acids ("Pro-coral Zooton" and "Pro-coral Organic"; Tropic Marin ${ }^{\circledR}$, Germany).

\section{Coral filter units}

Custom made perspex tiles $(10 \mathrm{~cm} \times 16.5 \mathrm{~cm} \times 0.6 \mathrm{~cm})$ with evenly distributed drill holes served as growth plates. Flat fragments of Stylophora pistillata coral were attached between these holes using cyanoacrylate adhesive (Fig. 2a). Filter supports (Costar Transwell@ permeable supports, Corning Incorporated) consisted of a polycarbonate membrane with $0.4 \mu \mathrm{m}$ pore size, $10^{8}$ pores and an area of $33 \mathrm{~mm}^{2}$, fixed onto a hollow 
polystyrene filter support (Fig. 2b). Excess material of the filter support was cut off, leaving a membrane covered cylinder (Fig. 2c). Plastic edges were carefully removed and rounded using a fine diamond file. The trimmed filter support was then filled with a small foam cylinder to reduce the growth of algae and bacteria and pushed in from below through the drill holes until they matched the tile's level (Fig. 2d). The coral colony fragments flatly grew over the entire growth plate, including filter supports mounted in the holes, laterally connecting to each other (Fig. 2d). Regular trimming of the coral prevented the colony from growing over the edges of the growth plates. When coral branched out, branches were carefully removed to prevent shading and ensure a homogenous pigmentation of the coral tissue.

After an average growth period of $102 \pm 9$ days coral had successfully overgrown the entire permeable filter support and reached a thickness of ca. $0.8 \mathrm{~mm}$, which is mainly attributed to the aragonitic skeleton. The readily overgrown coral filter unit (CFU) was carefully detached from the surrounding coral colony by using a dental drill (FBS 12/EF, Proxxon, Germany). To remove the CFU from its growth plate, it was pushed upwards through the drill hole, thereby reducing the risk of detaching the coral from the filter support. After trimming the coral to the size of the filter support, the CFU recovered in the culturing aquarium for seven to ten days allowing the coral tissue to heal and grow onto the polystyrene cylindrical filter support to tightly seal the formerly exposed skeletal rim. All CFUs were consecutively numbered and were allowed to overgrow the filter support up to $1 / 3$ of its height (Fig. 2e). To assess the ratio between polyp and coenosarc of CFUs, top view pictures were taken to determine area cover and polyp count using Image J. We counted $84 \pm 6$ polyps per $\mathrm{cm}^{2}$ representing $9.6 \pm 1.6 \%$ of the total CFU area (mean $\pm 1 \mathrm{sd}, \mathrm{n}=10$ ). Typically the tissue thickness of Stylophora pistillata (oral and aboral epithelium) is approximately $50 \mu \mathrm{m}$ (Tambutté et al. 2007). Prior to each 
Ussing chamber experiment, CFUs were visually checked for healthy and intact coral tissue. Suitable CFUs were identified by normal polyp expansion and even pigmentation. Additional checks using a binocular ensured that there was no algal overgrowth or damaged tissue exposing coral skeleton.

For measurements of pure skeleton, CFUs were bathed in $10 \% \mathrm{NaOCl}$ for $30 \mathrm{~min}$ followed by several rinses with ultra-pure water to remove any coral tissue.

\section{Ussing chamber}

Electrophysiological measurements on coral filter units (CFUs) were conducted in commercially available Ussing chambers designed for permeable supports (EP Devices, Belgium, Fig. 3a). This system allows independent perfusion of the tissue and skeleton side separated by tightly fitted Transwell membrane filter inserts (Fig. 3b). To prevent any tissue damage the bore diameter of the lower chamber was increased by $2 \mathrm{~mm}$ and the specimen was carefully mounted backwards from this side. Mounting was facilitated by a custom made rawlplug-like insertion device (Suppl. Fig. 1). The device consists of a hollow insertion punch made from Teflon which tightly spans in the inside of the permeable filter support when a steel core (V4A) is pushed into the punch. Light was provided by an LED facing the tissue side of the mounted CFU (Fig. 3). For similar light conditions in the Ussing chamber and the culturing tank, light spectra as well as the light densities in the culturing aquarium were recorded using a hyperspectral quantum sensor (RAMSES, TriOS Science) and compared to spectra of different LED lights. The best match was provided by a white LED (10000K MCD, scattering angle $20^{\circ}$, $5 \mathrm{~mm}$, white; Conrad, Germany), providing a dominant light peak between $430 \mathrm{~nm}$ and $470 \mathrm{~nm}$ and a broader peak covering 500 to $640 \mathrm{~nm}$ (Suppl. Fig. 2). The LED light was glued into a plastic cylinder and inserted into a specially fitted shaft in the center of the bottom lid of the Ussing chamber facing the coral tissue. It provided evenly distributed 
light over the mounted CFU (Fig. 3a). LED was connected to a custom made controlling box. Light densities could be altered stepwise, with a maximum photon flux density (pfd) of $234 \mu \mathrm{mol}$ photon $\mathrm{m}^{-2} \mathrm{~s}^{-1}$, which matches the light densities in the culturing aquarium (Suppl. Fig. 2).

\section{Experimental procedures}

The Ussing chamber experiments were performed at the Institute of Physiology, Christian-Albrecht-University (CAU) Kiel, Germany. After CFU mounting, the chambers were carefully flushed with seawater made from single salts, with a composition modified from Broecker and Peng (1982), here referred as artificial seawater (ASW, Tab. 1). CFUs remained visually and electrically stable and polyp expansion remained the same as in culture conditions. To avoid potential damage of coral tissue skeletal thickness of each CFU was determined after the experiment using a sliding caliper. Under control conditions both half-chambers were perfused with ASW, preheated to a constant temperature of $25^{\circ} \mathrm{C}(2 \mathrm{x}$ SH-27B, $1 \mathrm{x}$ TC334B, Warner Instrument Corporation). Other seawater solutions were prepared as given in Tab. 1. Osmolality of all solutions was determined using a cryoscopic osmometer (Osmomat 030; Gonotec, Germany). The pH was adjusted to 8.2 by addition of $\mathrm{NaOH}$ or $\mathrm{HCl}$, respectively. To test for active calcification of CFUs in the Ussing chambers, experiments were carried out in the light (see next section). Light/dark experiments on CFUs showed no influence of light on electrical resistance, therefore experiments were generally conducted in the dark to avoid light stress. The volume of each half-chamber was $1.95 \mathrm{~mL}$. To minimise boundary layer effects and ensure effective exchanges in bath composition, we used flow rates of 5 to 6 $\mathrm{mL} \mathrm{min}^{-1}$ resulting in 95\% exchange in 1 minute. At this rate, CFUs in the Ussing chamber maintained their normal polyp expansion as a sign of normal vitality. Flow rates of both half-chambers were synchronised and controlled either by a peristaltic pump (ISM $832 \mathrm{~A}$; 
Ismatec, Switzerland) or by gravity.

The electrical measurements were performed in open-circuit mode with reference to the tissue side. Continuous perfusion of both half-chambers and working in open-circuit mode ensured highest precision and stable conditions for electrical recordings.

Transepithelial potential across the entire coral was measured by voltage electrodes (Fig. 3a) positioned closely at both sides of the CFU. The respective $\mathrm{Ag} / \mathrm{AgCl}$ electrodes were connected to the chamber solution via $3 \mathrm{M} \mathrm{KCl} \mathrm{/} \mathrm{2.5 \%} \mathrm{Agar} \mathrm{bridges} \mathrm{to} \mathrm{keep} \mathrm{the} \mathrm{liquid}$ junction potential between the agar bridge and the seawater solution as low and stable as possible. Short current pulses $\Delta \mathrm{I}(0.1$ to $1 \mu \mathrm{A}, 500 \mathrm{~ms}$ pulse duration; current clamp technique) were injected with $\mathrm{Ag} / \mathrm{AgCl}$ current electrodes causing voltage deflections of the tissue $\left(\Delta V_{\text {te }}\right)$ (Fig. 3a). All electrodes were connected to an UPG3 pulse generator and amplifier (AD-Elektronik, Freiburg, Germany) and the voltage was recorded versus time by a paper chart recorder (Kipp und Zonen) (Fig. 4). The voltage recording was determined to a precision of $0.1 \mathrm{mV}$. Area related transepithelial resistance $\mathrm{R}_{\mathrm{te}}\left(\Omega \mathrm{cm}^{2}\right)$ was calculated as

$$
R_{t e}=\frac{\Delta V_{t e} \times \text { area }}{\Delta I}
$$

where area is the surface area of the CFU. Transepithelial resistance $\left(\mathrm{R}_{\mathrm{te}}\right)$ calculated from recorded voltage deflections could be determined to a precision of $1 \%$. The measurement of epithelial ion selectivity was performed in the presence of different solutions on each side of the tissue. Under these conditions liquid junction potentials between half-chamber solutions and $\mathrm{KCl}$ electrodes are different and the measured voltage change $(\Delta V)$ has to be corrected appropriately to obtain the diffusion potential $\left(V_{D}\right):$

$V_{D}=\Delta V-L J P$ 
We calculated the total liquid junction potential (LJP) according to Barry and Lynch (1991) using the ion activities and ion mobilities of the experimental solutions (c.f. supplementary information).

\section{Calcification experiments}

To determine calcification rates of CFUs in the Ussing chamber, we randomly selected 4 CFUs for alkalinity anomaly measurements. Calcification rates were determined by reduction in total alkalinity (TA) over time. The CFU was mounted into the Ussing chamber, perfused with ASW, and lit by LED light. Light intensity of 60 pfd was chosen to avoid light stress in the green to red spectral range (see Suppl. Fig. 2). For the experiment, ASW in each half-chamber was recirculated and TA determined at the beginning and the end of the experiment. Total alkalinity of $0.2 \mu \mathrm{m}$ filter sterilized ASW was measured by direct titration with hydrochloric acid according to Ivanenkov and Lyakhin (1978) using an open-cell titration vessel after Pavlova. TA could be determined to a precision of $18 \mu \mathrm{Eq} \mathrm{L}^{-1}(0.7 \%)$. Calibration was carried out with seawater standard (IAPSO, batch no. 155). Ammonia concentrations were determined using standard photometric procedures (Grasshoff et al. 1999). Concentrations in all samples were below $4 \mu \mathrm{M}$. Change in TA was therefore attributed to the reduction in carbonate alkalinity caused by calcification. Calcification rates (Cal, $\mu \mathrm{mol} \mathrm{CaCO}_{3} \mathrm{~cm}^{-2} \mathrm{~h}^{-1}$ of CFU) were calculated using the equations 3 and 4 :

$\Delta T A=T A_{f}-T A_{i}$

$C a l=\frac{\frac{\Delta T A}{2} \times V_{\text {chamber }}}{t \times A_{C F U}}$

Where $\mathrm{TA}_{\mathrm{f}}\left(\mathrm{mEq} \mathrm{kg}{ }^{-1}\right)$ is the final alkalinity, $\mathrm{TA}_{\mathrm{i}}$ is the initial alkalinity, $\mathrm{V}_{\text {chamber }}$ is the volume of the chamber, $\mathrm{t}$ is the duration of incubation and $\mathrm{A}_{\mathrm{CFu}}$ the area of the CFU. The 
surface area of $1.4 \pm 0.1 \mathrm{~cm}^{2}$ was calculated by gauging the corals' coverage of the holder assuming a cylinder.

\section{Assessment}

\section{Pre-experimental development of CFUs}

After extraction of coral filter units (CFUs) from growth plates, microcolonies showed viable coral tissue and net calcification under culturing conditions in the aquarium. Initially covering an average area of $0.58 \mathrm{~cm}^{2}$, CFUs healed by laterally expanding their tissue and skeleton. Additionally the part of the skeleton covering the membrane of the filter support increased in thickness over time. Starting with an average skeletal thickness of $0.8 \pm 0.35 \mathrm{~mm}($ mean $\pm 1 \mathrm{sd}, \mathrm{n}=7$ ) after extraction, CFUs showed an average thickness increase of $5 \pm 4 \mu \mathrm{m} \mathrm{d}^{-1}$ over time periods of approximately 5 months of growth in the culturing aquarium. Assuming a skeleton density of $1.8 \pm 0.2 \mathrm{~g} \mathrm{~cm}^{-3}$ for Stylophora pistillata (Libermann et al. 1995, Tambutté et al. 2015) the rate corresponds to $3 \pm 2 \mu \mathrm{mol}$ $\mathrm{CaCO}_{3} \mathrm{CFU}^{-1} \mathrm{~d}^{-1}\left(375 \pm 290 \mathrm{nmol} \mathrm{CaCO}_{3} \mathrm{~cm}^{-2} \mathrm{~h}^{-1}\right.$, mean $\left.\pm 1 \mathrm{sd}, \mathrm{n}=7\right)$.

\section{Calcification rates}

The TA anomaly experiments showed that in Ussing chamber experiments CFUs actively calcified in the light at an average rate of $150 \pm 40 \mathrm{nmol} \mathrm{CaCO} \mathrm{cm}^{-2} \mathrm{~h}^{-1}($ mean $\pm 1 \mathrm{sd}, \mathrm{n}=4)$, similar to the mean growth rate of CFUs in the culturing aquarium. These calcification rates are in the range of published values for S. pistillata, ranging approximately from 100 to $1000 \mathrm{nmol} \mathrm{cm}^{-2} \mathrm{~h}^{-1}$ (Furla et al. 2000, Moya et al. 2006, Mass et al. 2007, Holcomb et al. 2014).

\section{Reproducibility of Ussing chamber recordings}


To assess the reproducibility of our measurements we conducted long-term experiments with continuous measurements (pulse duration $500 \mathrm{~ms}$, pulse frequency of $0.125 \mathrm{~Hz})$ of rresistance $\left(\mathrm{R}_{\mathrm{te}}\right)$ and transepithelial voltage $\left(\mathrm{V}_{\mathrm{te}}\right)$ with durations of up to 6 hours. Over this period of time $\mathrm{R}_{\text {te }}$ and $\mathrm{V}_{\text {te }}$ of CFUs remained in a narrow range (changes $\leq 2 \%$ and $\leq 0.2 \mathrm{mV}$, respectively; Suppl. Tab. 1). A unique advantage of the mounting system is the option of repetitive use of the same CFU in a series of paired experiments with recovery phases in the culturing aquarium. Repeat measurements of CFUs over time periods of up to 17 weeks reproduced resistance values within a range of up to $\pm 10 \%$ in few cases up to $\pm 30 \%$ (Suppl. Tab. 2).

\section{Resistance of CFU}

The resistance value $R_{t e}$ as measured in this approach is the sum of three resistors in series, namely the permeable support, the skeleton, and the coral tissue. The permeable support alone had an almost negligible resistance of $8.3 \pm 1.2 \Omega \mathrm{cm}^{2}(\mathrm{n}=5)$, support with skeleton showed a resistance ranging from 44 to $325 \Omega \mathrm{cm}^{2}$ (average $135 \pm 40 \Omega \mathrm{cm}^{2}$, $n=6)$. Whole mounted CFUs showed transepithelial resistance values $\left(R_{t e}\right)$ reaching up to $13 \mathrm{k} \Omega \mathrm{cm}^{2}$ (545 to $12870 \Omega \mathrm{cm}^{2}$, average $3216 \Omega \mathrm{cm}^{2} \pm 344, \mathrm{n}=57 ;$ Fig. 5). High resistances were measured in actively calcifying CFUs (determined by reduction in TA). The bare skeleton contributed little to the overall $\mathrm{R}_{\mathrm{te}}$ of CFUs. $\mathrm{R}_{\mathrm{te}}$ was independent of skeleton thickness within the tested range ( 0.8 to $\sim 3.5 \mathrm{~mm}$ skeleton; Fig. 5) and showed a large variability between different CFUs. The polyp to coenosarc ratio varied by only $\pm 17 \%$ and therefore cannot account for the large $\mathrm{R}_{\text {te }}$ variability of CFUs. Furthermore, there were no differences in resistances between light and dark conditions.

Based on these observations we suggest that $R_{\text {te }}$ values mainly reflect coral tissue properties. Since the oral tissue is most likely of low resistance $\left(15 \pm 3\right.$ to $23 \pm 5 \Omega \mathrm{cm}^{2}$ in sea anemone Anemonia viridis, like S. pistillata a member of the Anthozoa: Hexacorallia; 
Bénazet-Tambutté et al. 1996, Tambutté et al. 2012), our measurements mainly reflect the properties of the aboral actively calcifying epithelium.

\section{Modulation of junctional tightness}

As $\mathrm{R}_{\mathrm{te}}$ depends on both, transcellular and paracellular resistance we tested the contribution of the paracellular pathway to magnitude and variability of $\mathrm{R}_{\text {te }}$ values.

Experiments with other tight epithelia showed that exposure to hyper-osmotic solutions (Tambutté et al. 2012) or low $\mathrm{Ca}^{2+}$ (Martinez- Palomo et al. 1980) caused a reduction in paracellular tightness. Perfusion of CFUs by 18\% increased osmolality (addition of glycine, ASW + Gly) resulted in a significant drop in Rte. Figure 6 shows three representative CFUs selected from a data set of 11 CFUs (Fig. 7). $R_{\text {te }}$ of CFUs reached equilibrium after about 2 hours of exposure and was fully reversible (data not shown). Control experiments performed on bare skeletons showed no change in $\mathrm{R}_{\mathrm{te}}$ when exposed to hyper-osmotic seawater (Suppl. Tab. 3). Comparable results were obtained after the exposure to $\mathrm{Ca}^{2+}$ free solution (Tab. 1). Again, these experiments were independent from skeleton thickness and reversible. Interestingly, the magnitude of $\mathrm{R}_{\mathrm{te}}$ in both experiments seemed to correlate with tightness of the corals under control conditions: The higher initial $\mathrm{R}_{\mathrm{te}}$ the steeper the rate of declining $\mathrm{R}_{\mathrm{te}}$ in response to the treatment. This indicates the presence of a lower $\mathrm{R}_{\mathrm{te}}$ threshold value above which the tightness depended only on paracellular properties. To evaluate this observation we plotted the deepest decline of $\mathrm{R}_{\mathrm{te}}$ over time $\left(\Delta \mathrm{R}_{\mathrm{te}} / \Delta \mathrm{t}\right)$ against the initial resistances of CFUs before treatment with ASW + Gly and Cafree ASW, respectively (Fig. 7). Data show an inverse correlation between initial $R_{t e}$ and rate of decline during the treatments with a threshold value of about $1 \mathrm{k} \Omega \mathrm{cm}^{2}$. A regression analysis of the hyper-osmotic treatment data (ASW+Gly) resulted in

$\Delta R_{t e} / \Delta t\left[\Omega \mathrm{cm}^{2} / \mathrm{s}\right]=-0.00198 \pm 0.00003 \times R_{t e, \text { initial }}\left[\Omega \mathrm{cm}^{2}\right]+0.123 \pm 0.096$ 
$R^{2}=0.96 ; n=11 ; p=3 \times 10^{-7}$

We conclude above $1 \mathrm{k} \Omega \mathrm{cm}^{2}$ vital tissue is actively involved in establishing high resistance barriers against passive ion flux across coral epithelia. Variations in these high resistance barriers of CFUs are determined by the integrity of the paracellular junctions.

\section{Active ion transport}

$\mathrm{V}_{\text {te }}$ values were inhomogenously distributed and ranged from $+3 \mathrm{mV}$ to $-3 \mathrm{mV}$. The underlying active transport current (ISc) was calculated. The resulting frequency distribution of the Isc values is shown in figure 8. The data shows a bimodal distribution with two transport current maxima around +0.24 and $-0.24 \mu \mathrm{A} \mathrm{cm}^{-2}$ indicating an active generation of a transepithelial potential and a weak net ion transport across the entire coral tissue. Interpretation of magnitude, underlying mechanisms, and origin of transport direction requires further investigations.

\section{Ion selectivity}

To investigate the ion selectivity of CFUs, we continuously perfused with ASW on the tissue side and low NaCl ASW (Tab. 1) on the skeleton side. The resulting change in the transepithelial voltage depends on the preference of the paracellular pathway for either $\mathrm{Na}^{+}$or $\mathrm{Cl}^{-}$(Fig. 1b). Under the given experimental conditions, the diffusion potential was positive indicating cation selectivity (Fig. 4). $\mathrm{R}_{\text {te }}$ remained stable during the treatment and the effect of the low $\mathrm{NaCl}$ ASW treatment was completely reversible. The bare skeleton did not generate any diffusion potential $\left(\mathrm{V}_{\mathrm{D}}<0.05 \mathrm{mV}\right)$.

Interestingly corals of lower tightness showed less cation selectivity compared to high resistance CFUs. To analyse this observation in detail, $V_{D}$ was plotted against $R_{\text {te }}$ (Fig. 9). The data shows that $V_{D}$ increased with $R_{t e}$ up to a resistance of $3-4 \mathrm{k} \Omega \mathrm{cm}^{2}$ to reach a plateau at higher $\mathrm{R}_{\mathrm{te}}$ values. 
Since the ion selectivity and $\mathrm{R}_{\text {te }}$ are predominantly controlled by the properties of the paracellular pathway, these results represent CFUs at different functional states of the paracellular pathway. CFUs with intermediate resistance display a nonselective functional state, while high resistance CFUs are cation selective.

\section{Discussion}

\section{Methodology}

Our approach aims at the electrophysiological characterization of coral tissue in vivo. Several points shown in the Assessment have demonstrated its suitability in this respect. Electrical resistance measurements on CFUs are reproducible on short and longer time scales. Furthermore, induced and reversible reduction of $R_{\text {te }}$ by manipulation of paracellular pathways proves that our approach is suitable to monitor tissue ion permeability. Previous assays applied a different approach (Tambutté et al. 2012). Microcolonies of the coral S. pistillata were cultured over perforated glass slides with a small hole on which the apex of the coral was placed. The coral grew above this hole by expanding its skeleton and tissues over the glass slide. Hence, the skeleton above the hole was thicker and the area to assess the tissue was small opposed to our new approach. The new CFU preparation assay increases the ratio of tissue to skeleton resistance by about 1 order of magnitude compared to previous assays (Tambutté et al. 2012). The geometry of our CFUs simplifies the assessment of the electrogenic surface area and allows an easier comparison with other biological tissues. The applied current clamp technique does not force electrolytes or ions through the tissue and thus avoids artefacts of abnormal ion transport. Continuously perfused chambers avoid hydrostatic pressure gradients across the tissue. The set-up offers the opportunity to combine 
electrophysiological measurements with other analytical methods in response to chemical and physical parameters.

Our method is limited to the assessment of net charge transport ( $\mathrm{I}_{\mathrm{sC}}$ ) across entire corals, which represents the sum of multiple ion fluxes. It is only applicable to corals, which are able to laterally overgrow substrates, and to microcolonies. Illumination by a single LED does not allow mimicking the complete spectral characteristics provided in the culturing aquarium or in natural reefs.

\section{Application}

The mechanisms of calcification in corals are still a matter of debate since data on coral epithelial properties are still limited. On the other hand, data are urgently needed to adjust models for proxy interpretation. Calcification occurs in the extracellular calcifying medium (ECM) (Allemand et al. 2010) between the calicoblastic epithelium and the skeleton at the aboral side of the coral. Key questions are i) to what extent the coral is able to seal this compartment against seawater? and ii) what is the contribution of the transcellular and the paracellular pathways, respectively, to provide ions such as $\mathrm{Ca}^{2+}$ and carbonate to the site of skeleton formation?

The aim of this study was to develop a non-invasive assay to monitor and characterise epithelial properties of coral tissue in vivo, using electrophysiological measurements. The non-invasive approach implied that the coral had to be investigated as a whole organism. This required some assumptions and simplifications as the coral tissue consists of four epithelial layers in series (Fig. 1c). Both layers of the oral tissue in other cnidaria have been described as very leaky in comparison to our measured total resistance values of the whole coral (Bénazet-Tambutté et al. 1996, Tambutté et al. 2012). Similarly, skeleton and permeable support contribute little to the total resistance. Assuming a similarly leaky oral epithelium for S. pistillata as described in other cnidaria, 
our approach provides data for the aboral tissue, still describing both layers as a functional unit. In contrast to previous preparations (Tambutté et al. 2012), the present CFU preparation had the advantage of a thinner and defined skeleton thickness of around $1 \mathrm{~mm}$ with a simple planar geometry and a small contribution to resistance at low variability. The access to ECM is thereby only restricted by a small electrical resistance allowing the exchange of ions during experiments. Interestingly, the CFU resistance did not depend on skeleton thickness (Fig. 5), indicating that the tightness of the coral is independent of the skeleton.

We obtained resistance values for the epithelium, which are in agreement with previous measurements (Tambutté et al. 2012), with even higher tightness up to $12 \mathrm{k} \Omega \mathrm{cm}^{2}$. Clearly, Stylophora pistillata forms a tight epithelium (Frömter and Diamond 1972; Lewis 1996) to seal the ECM from lateral or transepithelial seawater access, as suggested before (Tambutté et al. 1996; Allemand et al. 2010; Venn et al. 2011). By two independent, although unspecific treatments we were able to reversibly open the paracellular pathways. These experiments revealed a substantial role of septate junctions, forming the paracellular strands in the control of epithelial tightness. The large range of epithelial resistance values could not be explained in this study. We measured CFUs at different polyp expansion and illumination states and could not detect any effect on transepithelial resistance. Actively calcifying CFUs in the calcification experiments were in the same resistance range. As mentioned above epithelial resistance values varied independently of skeleton thickness. The preparation and culture technique most likely excludes an accidental leak as a cause of this variation since we could use CFUs repetitively and over long time periods without a change of the individual resistance value. We hypothesize that the coral is able to functionally control 
paracellular resistance; however, even at the lowest values paracellular ion transport is not sufficient for skeleton formation as discussed below.

These results are in conflict with some models for proxy incorporation in scleractinian corals, which have described the site of calcification in terms of a leaky system largely open to ion exchange with seawater (e.g. Adkins et al. 2003, Cohen and McConnaughey 2003, Allison et al. 2011, Allison et al. 2014, Gagnon et al. 2012, Saenger and Erez 2016). To support their high calcification rates scleractinian corals have to maintain a high ion flux from seawater through their tissues to the skeleton. Assuming that resistance in paracellular pathways is inversely related to charge transport by ion diffusion, we bring together our results and published data (Bénazet-Tambutté et al. 1996, Furla et al. 1998, Tambutté et al. 2012). Based on that the estimated relative contribution of the coral tissue layers to passive (diffusional) ion permeabilities can be estimated to be $1 / 0.007$ for oral relative to aboral tissue. This ratio is based on the average resistance values for oral and aboral tissues of ca. $20 \Omega \mathrm{cm}^{2}$ and $3000 \Omega \mathrm{cm}^{2}$, respectively. This raises the question whether this very low passive diffusional permeability of aboral tissue would suffice to maintain calcification or not. Calcification rates for S. pistillata were measured in several studies being in the range of 130 to $990 \mathrm{nmol} \mathrm{CaCO}_{3} \mathrm{~cm}^{-2} \mathrm{~h}^{-1}$ (Tambutté et al. 1996, Furla et al. 2000, Holcomb et al. 2014). Our measurements are in good agreement with these data $\left(375 \mathrm{nmol} \mathrm{CaCO} \mathrm{cm}^{-2} \mathrm{~h}^{-1}\right.$ and $150 \mathrm{nmol} \mathrm{CaCO}_{3} \mathrm{~cm}^{-2} \mathrm{~h}^{-1}$ under culture conditions and in Ussing chamber, respectively). Tambutté et al. (1996) determined a $\mathrm{Ca}^{2+}$ exchange rate of $0.17 \mathrm{~min}^{-1}$ across the oral epithelium, corresponding to an exchange flux of about $2000 \mathrm{nmol} \mathrm{Ca}{ }^{2+} \mathrm{cm}^{-2} \mathrm{~h}^{-1}$ consequently being sufficient to maintain calcification. However, the diffusional $\mathrm{Ca}^{2+}$ flux through the aboral epithelium, which represents $<1 \%$ of the oral epithelium permeability, can provide less than $10 \%$ of the $\mathrm{Ca}^{2+}$ necessary for calcification. 
Alternatively, some previous models assumed that $\mathrm{Ca}^{2+}$ for calcification could be supplied by active seawater transport (Saenger \& Erez, 2016). Based on the tight tissue properties of S. pistillata, that indicate a very limited pore area through which seawater can flow, very high flow velocities through the tissue would be necessary which would require application of very high hydraulic pressure to maintain calcification. A discontinuous seawater flow would result in even higher velocities. A complete opening of the tissue would have been detectable with our method indicated by low resistance values, which were not observed. Finally, our method cannot detect transcytosis (vesicle transport). However, transcytosis has never been observed in S. pistillata (e.g. Barott et al. 2015).

Consequently, we suggest that the aboral tissue permeability of $S$. pistillata is too low to allow sufficient passive diffusion of ions. It likely indicates a predominantly transcellular aboral pathway for active $\mathrm{Ca}^{2+}$ transport to the site of calcification to maintain high calcification rates.

Tambutté et al. (2012) studied calcein uptake into the skeleton in S. pistillata and found that this bulky dye molecule was taken up through the paracellular pathway with a calcein/ $\mathrm{Ca}^{2+}$ ratio of $10^{-5}$. On first sight this finding seems to contradict a highly resistant and ion selective pathway. However, different paracellular pathways for small ions and large macromolecules occur in the tricellular tight junctions in mammalian tissues. The parallel arrangements of junction proteins select for small ions and synchronously transport bulky molecules (Krug et al. 2009, Shen et al. 2011). The large tricellular tubes contribute about $1 \%$ to the paracellular permeability and could therefore allow a sufficient flux of the rare calcein macromolecules. Whether a similar junction type occurs in corals, however, is not known. 
The restricted passive diffusional exchange across the aboral tissue provides important constraints on models of coral calcification and the uptake of trace elements and isotopes.

To provide sufficient inorganic carbon and alkalinity for calcification the $\mathrm{Ca}^{2+}$ flux has to be accompanied by an equivalent $\mathrm{CO}_{2}$ and/or $\mathrm{HCO}_{3}$ - flux to the site of calcification. Like for $\mathrm{Ca}^{2+}$, diffusional $\mathrm{HCO}_{3}{ }^{-}$and $\mathrm{H}^{+}$fluxes are limited by the low paracellular ion permeability of the aboral tissue. In contrast to the limited passive diffusion of $\mathrm{HCO}_{3}{ }^{-}$, $\mathrm{CO}_{2}$ can freely permeate aboral cell layers and could thereby provide sufficient carbon for calcification. However, the slow diffusional removal of the resulting $\mathrm{H}^{+}$ions would not allow maintaining the observed high calcification rates. Thus, protons generated through the formation of $\mathrm{CaCO}_{3}$ must be actively removed from the site of calcification to avoid acidification and inhibition of precipitation. Consequently, our Ussing chamber experiments support the hypothesis that alkalinity as well as $\mathrm{Ca}^{2+}$ fluxes require active transcellular transport through the aboral tissue layer to maintain the typical calcification rates of $S$. pistillata.

In support of the active ion transport, we detected a small but consistent short-circuit current (Isc) indicating net electrogenic transport across the entire coral tissue. The variable sign of the Isc (Fig. 8) may derive from a superposition of variable fluxes across four cell layers. The pathways responsible for the generation of this Isc and their location will represent an important question for future studies to better understand electrogenic transport in coral tissues.

In summary, our assay allows the electrophysiological characterisation of ion transport and tissue permeability. Furthermore, it offers the opportunity to combine electrophysiological measurements with other analytical methods such as chemical and isotopic analyses and pharmacological inhibitors. The assay is non-invasive and 
performed in vivo, i.e. no separation of coral tissue from skeleton; no voltage clamp (only injections of short current pulses); and continuous control of solutions and electrophysiological access to both sides of the aboral calcifying tissue. With this assay, we detected a high resistance epithelium in calcifying S. pistillata depending on paracellular properties with low contribution of the skeleton.

\section{Outlook}

The technical approach presented here now offers the chance to further analyse the functional transport properties of the aboral tissue under different environmental conditions e.g. illumination, salinity, $\mathrm{pH}$, and temperature. These investigations will help to gain insight into the mechanisms and regulation of transepithelial transport to better understand calcification in scleractinian corals. Finally, the method has a high potential to improve proxy interpretation in corals and can be applied to other corals like Acropora and Pocillopora and encrusting organisms.

\section{References}

Adkins J., Boyle E., Curry W., Lutringer A. 2003. Stable isotopes in deep-sea corals and a new mechanism for "vital effects". Geochim. Cosmochim. Acta 67, 1129-1143.

Allemand D., Ferrier-Pagès C., Furla P., Houlbrèque F., Puverel S., Reynaud S., Tambutté E., Tambutté S., Zoccola D. 2004. Biomineralisation in reef-building corals: from molecular mechanisms to environmental control. Comptes Rendus Palevol 3:453-467

Allemand D., Tambutté E., Zoccola D., Tambutté S. 2010. Coral calcification, cells to reefs. In Dubinsky Z. [Ed.] Coral Reefs: an ecosystem in transition, 119-150, Springer, New York.

Allison N., Cohen I., Finch A.A., Erez J. 2011. Controls on Sr/Ca and Mg/Ca in scleractinian corals: The effects of Ca-ATPase and transcellular Ca channels on skeletal chemistry. Geochim. Cosmochim. Acta 75, 6350-6360.

Allison N., Cohen I., Finch A.A., Erez J., Tudhope A.W. 2014. Corals concentrate dissolved inorganic carbon to facilitate calcification. Nature comm. 5, 5741.

Barott K.L., Perez S.O., Linsmayer L.B., Tresguerres M., 2015. Differential localization of ion transporters suggests distinct cellular mechanisms for calcification and photosynthesis between two coral species. Am. J. Physiol.-Regulatory, Integrative and Comparative Physiology, 309, R235-R246.

Barry P.H., Lynch J.W. 1991. Liquid junction potentials and small cell effects in patchclamp analysis. J. Membr. Biol. 121, 101-117. 
Bleich M., Shan Q., Himmerkus N. 2012. Calcium regulation of tight junction

permeability. Annals of the New York Academy of Sciences 1258, 93-99.

Broecker W., Peng T. 1982. Tracers in the Sea. p. 692, Lamont-Doherty Geological

Observatory, Palisades.

Bénazet-Tambutté S., Allemand D., Jaubert J. 1996. Permeability of the oral epithelial layers in cnidarians. Mar. Biol. 126, 43-53.

Böhm F., Gussone N., Eisenhauer A., Dullo W., Reynaud S., Paytan A. 2006. Calcium isotope fractionation in modern scleractinian corals. Geochim. Cosmochim. Acta 70, 4452-4462.

Clode P., Marshall A. 2002. Low temperature FESEM of the calcifying interface of a scleractinian coral. Tissue Cell 34, 187-198.

Cohen A., McConnaughey T. 2003. Geochemical perspectives on coral mineralization. Rev. Mineral. Geochem. 54, 151-187.

Domart-Coulon I., Tambutté S., Tambutté E., Allemand D. 2004. Short-term viability of soft tissue detached from the skeleton of reef-building corals. J. Exp. Mar Biol. Ecol. 309, 199-217.

Frömter E., Diamond J. 1972. Route of passive ion permeation in epithelia. Nature New Biology 235, 9-13.

Furla P., Bénazet-Tambutté S., Jaubert J., Allemand D. 1998. Diffusional permeability of dissolved inorganic carbon through the isolated oral epithelial layers of the sea anemone Anemonia viridis. J. Exp. Mar Biol. Ecol. 221, 71-88.

Furla P., Galgani I., Durand I., Allemand D. 2000. Sources and mechanisms of inorganic carbon transport for coral calcification and photosynthesis. J. Exp. Mar Biol. 203, 34453457.

Gagnon A.C., Adkins J.F., Erez J. 2012. Seawater transport during coral biomineralization. Earth Planet. Sc. Lett. 329, 150-161.

Ganot P., Zoccola D., Tambutté E., Voolstra C. R., Aranda M., Allemand D., Tambutté S. (2015). Structural molecular components of septate junctions in cnidarians point to the origin of epithelial junctions in eukaryotes. Molecular biology and evolution, 32, 44-62.

Grasshoff K., Kremling K. Ehrhardt M. [eds.] 1999. Methods of seawater analysis. WileyVCH.

Greger R., Schlatter E. 1981. Presence of luminal K +, a prerequisite for active NaC1 transport in the cortical thick ascending limb of Henle's Loop of rabbit kidney. Pfug. Arch. Eur. J. Phy. 392, 92-94.

Hohn S., Merico A. 2015. Quantifying the relative importance of transcellular and paracellular ion transports to coral polyp calcification. Front. Earth Sc. 2, 37.

Holcomb M., Tambutté E., Allemand D., Tambutté S. 2014. Light enhanced calcification in Stylophora pistillata: effects of glucose, glycerol and oxygen. PeerJ 2, 375.

Ivanenkov V.N., Lyakhin Y. 1978. Determination of total alkalinity in seawater. In: Bordovsky O.K. and Ivanenkov V.N. [Eds.] Methods of Hydrochemical Investigations in the Oceans, p. 110-114, Nauka Publishing House.

Krug S.M., Amasheh S., Richter J.F., Milatz S., Günzel D., Westphal J.K., Huber O., Schulzke J.D., Fromm M., 2009. Tricellulin forms a barrier to macromolecules in tricellular tight junctions without affecting ion permeability. Molec. Biol. Cell, 20, 3713-3724.

Lewis S.A. 1996. Epithelial structure and function. In: Willis N.K., Reuss L., Lewis S.A. [Eds.] Epithelial Transport - A guide to methods and experimental analysis. p. 1-20, Chapman \& Hall, London. 
Liberman T., Genin A., Loya Y., 1995. Effects on growth and reproduction of the coral Stylophora pistillata by the mutualistic damselfish Dascyllus marginatus. Mar. Biol. 121, 741-746.

Lohrmann E., Burhoff I., Nitschke R.B., Lang H.J., Mania D., Englert H.C., Hropot M., Warth R., Rohm W., Bleich M., Greger R. 1995. A new class of inhibitors of cAMP-mediated $\mathrm{Cl}^{-}$ secretion in rabbit colon, acting by the reduction of cAMP-activated $\mathrm{K}^{+}$conductance. Pfug. Arch. Eur. J. Phy. 429, 517-530.

Lough J.M. 2008. Coral calcification from skeletal records revisited. Mar. Ecol. Progr. Ser. 373, 257-267.

Mass T., Einbinder S., Brokovich E., Shashar N., Vago R., Erez J., Dubinsky Z. 2007. Photoacclimation of Stylophora pistillata to light extremes: metabolism and calcification. Mar. Ecol.-Prog. Ser. 334, 93-102.

Mass T., Drake J.L., Haramaty L., Rosenthal Y., Schofield O.M., Sherrell R.M., Falkowski P.G. 2012. Aragonite precipitation by "proto-polyps" in coral cell cultures. PLoS One 7, 35049.

Martinez-Palomo A., Meza I., Beaty G., Cereijido M. 1980. Experimental modulation of occluding junctions in a cultured transporting epithelium. J. Cell Biol. 87, 736-745.

Moya A., Tambutté S., Tambutté E., Zoccola D., Caminiti N., Allemand D. 2006. Study of calcification during a daily cycle of the coral Stylophora pistillata: implications for 'light-enhanced calcification'. J. Exp. Biol. 209, 3413-3419.

Nakamura T., Nadaoka K., Watanabe A. 2013. A coral polyp model of photosynthesis, respiration and calcification incorporating a transcellular ion transport mechanism. Coral Reefs 32, 779-794.

Saenger C. and Erez J. 2016. A Non-traditional Stable Isotope Perspective on Coral Calcification, In: Goffredo S., Dubinsky Z. [Eds.] The Cnidaria, Past, Present and Future. p. 181-204, Springer, Basel

Shan C., Yang H., Song J., Han D., Ivaska A., Niu L. 2009. Direct electrochemistry of glucose oxidase and biosensing for glucose based on graphene. Anal. Chem. 81, 2378-2382.

Shen L., Weber C.R., Raleigh D.R., Yu D., Turner J.R., 2011. Tight junction pores and leak pathways: a dynamic duo. Ann. Rev. Physiol., 73, 283-309.

Tambutté E., Allemand D., Mueller E., Jaubert J. 1996. A compartmental approach to the mechanism of calcification in hermatypic corals. J. Exp. Biol. 199, 1029-1041.

Tambutté E., Allemand D., Zoccola D., Meibom A., Lotto S., Caminiti N., Tambutté S. 2007. Observations of the tissue-skeleton interface in the scleractinian coral Stylophora pistillata. Coral Reefs 26, 517-529.

Tambutté, E., Tambutté, S., Segonds, N., Zoccola, D., Venn, A., Erez, J., Allemand, D. 2012. Calcein labelling and electrophysiology: insights on coral tissue permeability and calcification. P. Roy. Soc. Lond. B. Bio. 279, 19-27.

Tambutté E., Venn A.A., Holcomb M., Segonds N., Techer N., Zoccola D., Allemand D., Tambutté S., 2015. Morphological plasticity of the coral skeleton under $\mathrm{CO}_{2}$-driven seawater acidification. Nat. Comm. 6.

Ussing H. 1953. Transport through biological membranes. Annu. Rev. Physiol. 15, 1-20.

Ussing H., Erlij D., Lassen U. 1974. Transport pathways in biological membranes. Annu.

Rev. Physiol. 36, 17-49.

Ussing H.H., Zerhan K. 1950. Active transport of sodium as the source of electric current in the short-circuited isolated frog skin. Acta Physiol. Scand. 23, 110-27.

Venn A., Tambutté E., Holcomb M., Allemand D., Tambutté S. 2011. Live tissue imaging shows reef corals elevate $\mathrm{pH}$ under their calcifying tissue relative to seawater. PloS one 6, 20013. 
Wright O., Marshall A. 1991. Calcium transport across the isolated oral epithelium of scleractinian corals. Coral Reefs 10, 37-40.

\section{Acknowledgements}

The authors would like to thank the workshops of the Institute of Physiology and the “Technik und Logistik Zentrum, GEOMAR” for the construction of special technical equipment, T. Stegmann for laboratory help, and the research group of M. Bleich for fruitful discussions. Many thanks to Yvonne Sawall for help with light measurements. We are grateful to Nele Wendländer, Svantje Gottschlich, Ela Kosiorek, Manuela Goos, Mahmoud AlKhatib, Mailin Pohlmann and Thal Müller for their indispensable support for coral maintenance and help for the preparation of experimental coral filter units. Finally we would like to thank two anonymous reviewers and the associate editor Dr. David Suggett for useful comments improving the manuscript.

\section{Funding}

German Federal Ministry of Education and Research (BMBF, FKZ 03F0608M),

“Biological impacts of ocean acidification (BIOACID)" project 3.3.2.

German Research Foundation (DFG), Trilateral Program TRION I (Ei 272/30-1), TRION

II (Ei 272/30-2), TRION II (Bl 422/6-2).

Government of the Principality of Monaco, Centre Scientifique de Monaco research program. 


\section{Figure legends}

Figure 1: Electrical Ussing chamber measurements. a) Epithelium depicted by white cells connected with cell junctions (filled circles) is mounted between half-chambers perfused with identical solutions. Ion transport proteins in the epithelium (white circles, top) generate a transepithelial voltage $\left(V_{\text {te }}\right)$ which is detected by voltage electrodes (top). Current electrodes (bottom) inject short current pulses $(\Delta \mathrm{I})$ which cause a voltage deflection $\left(\Delta V_{\text {te }}\right)$ across the resistance of the tissue. Transepithelial resistance $\left(R_{t e}\right)$ can be calculated by Ohm's law. The short circuit current (Isc) indicates transepithelial charge movement. b) An ion gradient across the epithelium (e.g. $\mathrm{NaCl}$ ) generates a diffusion voltage (V) if one ion species (e.g. the cation $\mathrm{Na}^{+}$) is preferentially conducted. Since cell membranes are two diffusion barriers in series, $\mathrm{V}$ mainly represents the ion selectivity of the paracellular pathways. c) Schematic cross section through coral grown over filter support (F) which is mounted between half-chambers (not drawn to scale). Cell layer structure of the coral tissue represents oral ectoderm (OEc) and endoderm (OEn) as well as aboral endoderm (AEn) and ectoderm (AEc). The AEc is composed of calicoblastic cells responsible for skeleton formation (Sk). Ions can reach the site of calcification via trans- and paracellular pathways.

Figure 2: Culture and preparation of coral filter units (CFUs). Fixed fragments of Stylophora pistillata flatly grow over the Perspex growth plate (a). Permeable filter support (b) was trimmed as indicated by the dashed line. Trimmed filter support (c) was pushed into a drill hole of Perspex tile (d) until it matched the tile's level. Front - freshly inserted filter, middle and back - filter partly overgrown by coral. Readily overgrown coral filters were cut out and recovered in the culturing aquarium. During recovery coral 
was allowed to laterally grow over $1 / 3$ of the cylinder of the filter support, thus tightly sealing the formerly exposed skeleton (e, side view).

Figure 3: Ussing chamber used in our setup. a) Photograph and schematic view (b) of Ussing chamber with tightly mounted CFU (1). The inflows (2) and outflows (3) ensure continuous perfusion of both half-chambers separated by the CFU. Each half-chamber is fitted with one voltage (4) and one current electrode (5), with the top one referring to the skeleton side and the lower one to the tissue side. Voltage reference was at the tissue side. LED light (6) is provided from a shaft in the bottom lid of the Ussing chamber and illuminates the coral tissue side of the CFU.

Figure 4: Typical Ussing chamber chart recording during experiment exposing CFU to ASW (Control, C) and low NaCl ASW (L). Transepithelial voltage $\left(\mathrm{V}_{\text {te }}\right)$ is plotted as a function of time. The spontaneous $V_{\text {te }}$ can be read from the upper margin of the recording. The voltage deflections $\left(\Delta \mathrm{V}_{\text {te }}\right)$ are caused by regular injections of short current pulses $(\Delta \mathrm{I})$ and reflect the transepithelial resistance. Exposing skeleton side (Sk) of CFU to low NaCl ASW (L) causes a shift in $\mathrm{V}_{\text {te }}(\Delta \mathrm{V})$ within time period $\Delta \mathrm{t}$. $\Delta \mathrm{V}$ is a measure of ion selectivity, in this case skeletal positive, i.e. cation pass preferentially to the skeletal side.

Figure 5: Transepithelial resistance ( $\left.\mathrm{R}_{\mathrm{te}}\right)$ of Stylophora pistillata CFU (diamonds) and bare skeletons (black triangles) plotted against height of the skeleton covering the filter. $\mathrm{R}_{\mathrm{te}}$ of most CFUs were measured under dark and light conditions. Individual $\mathrm{R}_{\mathrm{te}}$ values remained stable irrespective of illumination states. There was no correlation between $\mathrm{R}_{\mathrm{te}}$ and skeletal thickness. Contribution of the bare skeleton to the overall $\mathrm{R}_{\mathrm{te}}$ of intact 
CFUs was small as indicated by the $\mathrm{R}_{\text {te }}$ values of CFUs (grey diamonds) corresponding to the 6 skeletal data points.

Figure 6: Examples showing the responses of 3 representative CFUs (different symbols) to hyper-osmotic treatment. Transepithelial resistance $\left(\mathrm{R}_{\mathrm{te}}\right)$ declined when perfusion conditions changed from ASW (white background, left) to hyper-osmotic conditions (ASW + Gly, grey background, right). Response is smaller at lower initial Rte. Error bars $( \pm 1$ sd) are smaller than symbols.

Figure 7: Reduction in resistance of CFUs over time $\left(\Delta \mathrm{R}_{\mathrm{te}} / \Delta \mathrm{t}\right)$ in response to hyperosmotic seawater (ASW + Gly) and $\mathrm{Ca}^{2+}$-free ASW plotted against initial Rte. ASW + Gly values follow a linear trend (Eq. $5, \mathrm{R}^{2}=0.95, \mathrm{p}=3 \times 10^{-7}$ ). Horizontal dashed line indicates no response to the treatment, which occurs at initial $\mathrm{R}_{\mathrm{te}}<1 \mathrm{k} \Omega \mathrm{cm}^{2}$. Vertical dashed line indicates the initial $R_{\text {te }}$ of the CFU that showed the least reduction in resistance and lies within the 95\% confidence belt of the linear regression (Eq. 5).

Figure 8: Bimodal frequency distribution of the transport current intensities (IsC) derived from $V_{\text {te }}$ and $\mathrm{R}_{\mathrm{te}}$ in 32 CFUs under control conditions (ASW) in the dark. Counts represent numbers of CFUs in the specified ISC bins. CFUs show a small either negative or positive transport current indicating active, electrogenic ion transport across the entire coral tissue.

Figure 9: Transepithelial diffusion potentials $\left(V_{D}\right)$ in response to low $\mathrm{NaCl} A S W$ treatment plotted against transepithelial resistance ( $\left.R_{\text {te }}\right)$ of CFUs. Tissue side was continuously perfused with ASW. Skeleton side was perfused with low NaCl ASW. CFUs 
(white squares) show positive $V_{D}$ values indicating cation selectivity of the coral tissue.

$\mathrm{V}_{\mathrm{D}}$ increases with increasing $\mathrm{R}_{\mathrm{te}}$ up to about $4 \mathrm{k} \Omega \mathrm{cm}^{2}$. 


\section{Tables}

Table 1: Experimental seawater solutions

\begin{tabular}{|c|c|c|c|c|c|}
\hline & CSW & ASW & low NaCl ASW & Ca-free ASW & ASW + Gly \\
\hline & \multicolumn{5}{|c|}{ concentration [mmol L-1] } \\
\hline $\mathrm{NaCl}$ & 416 & 412 & 309 & 424 & 412 \\
\hline KCl & 9.50 & 10.2 & 7.65 & 10.2 & 10.2 \\
\hline $\mathrm{Na}_{2} \mathrm{SO}_{4}$ & 21.9 & 28.0 & 21.0 & 28.0 & 28.0 \\
\hline $\mathrm{MgCl}_{2} \cdot 6 \mathrm{H}_{2} \mathrm{O}$ & 55.6 & 53.0 & 39.8 & 55.0 & 53.0 \\
\hline $\mathrm{CaCl}_{2} \cdot 2 \mathrm{H}_{2} \mathrm{O}$ & 11.0 & 10.3 & 7.75 & 0.00 & 10.3 \\
\hline $\mathrm{NaHCO}_{3}$ & 2.47 & 2.35 & 1.76 & 2.35 & 2.35 \\
\hline Mannitol & - & - & 280 & - & - \\
\hline Glycine & - & - & - & - & 200 \\
\hline Glucose & - & - & - & - & - \\
\hline EGTA & - & - & - & 2.5 & - \\
\hline $\begin{array}{l}\text { Osmolarity } \\
\left(\text { mOsm L L }^{-1}\right)\end{array}$ & 1016 & 1019 & 1018 & 1020 & 1200 \\
\hline
\end{tabular}

CSW = culturing seawater from the aquarium made from sea salt mixture Tropic Marin ${ }^{\circledR}$ "Pro Reef"; ASW = artificial seawater made from single salts; low NaCl ASW = hyposaline, iso-osmotic ASW diluted with deionised water and added mannitol to match osmolarity of ASW; Ca-free ASW = omitted $\mathrm{CaCl}_{2}$ was replaced by additional $\mathrm{NaCl}$ and $\mathrm{MgCl}_{2}$ to match osmolarity of ASW, EGTA was added as $\mathrm{Ca}^{2+}$ buffer; ASW + Gly = Glycine was added to ASW to produce iso-saline, but hyper-osmotic seawater. 
Fig. 1
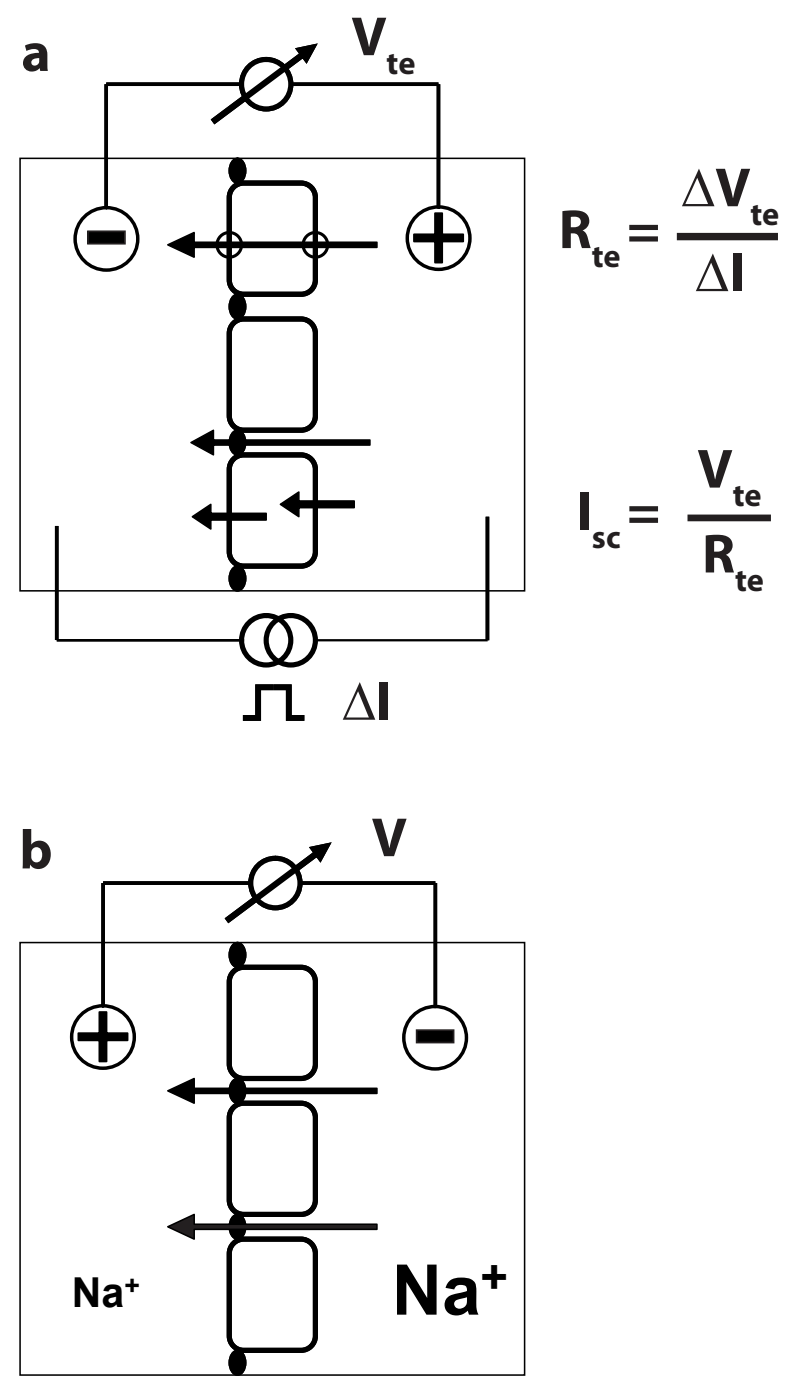

C

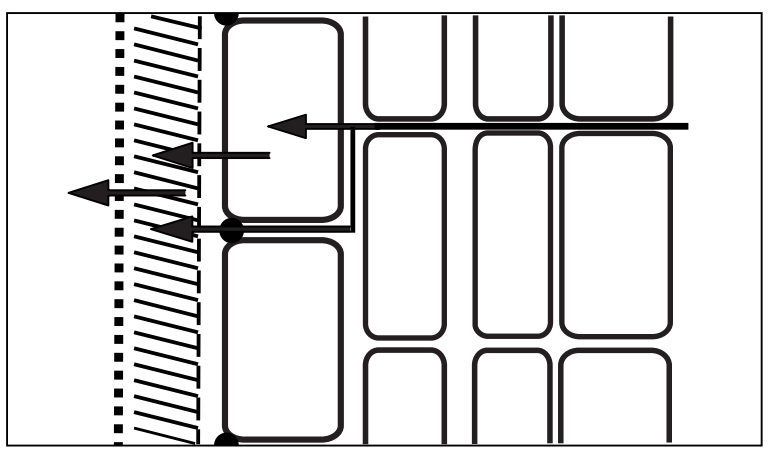

F Sk AEc AEn OEn OEc 
Fig. 2

a

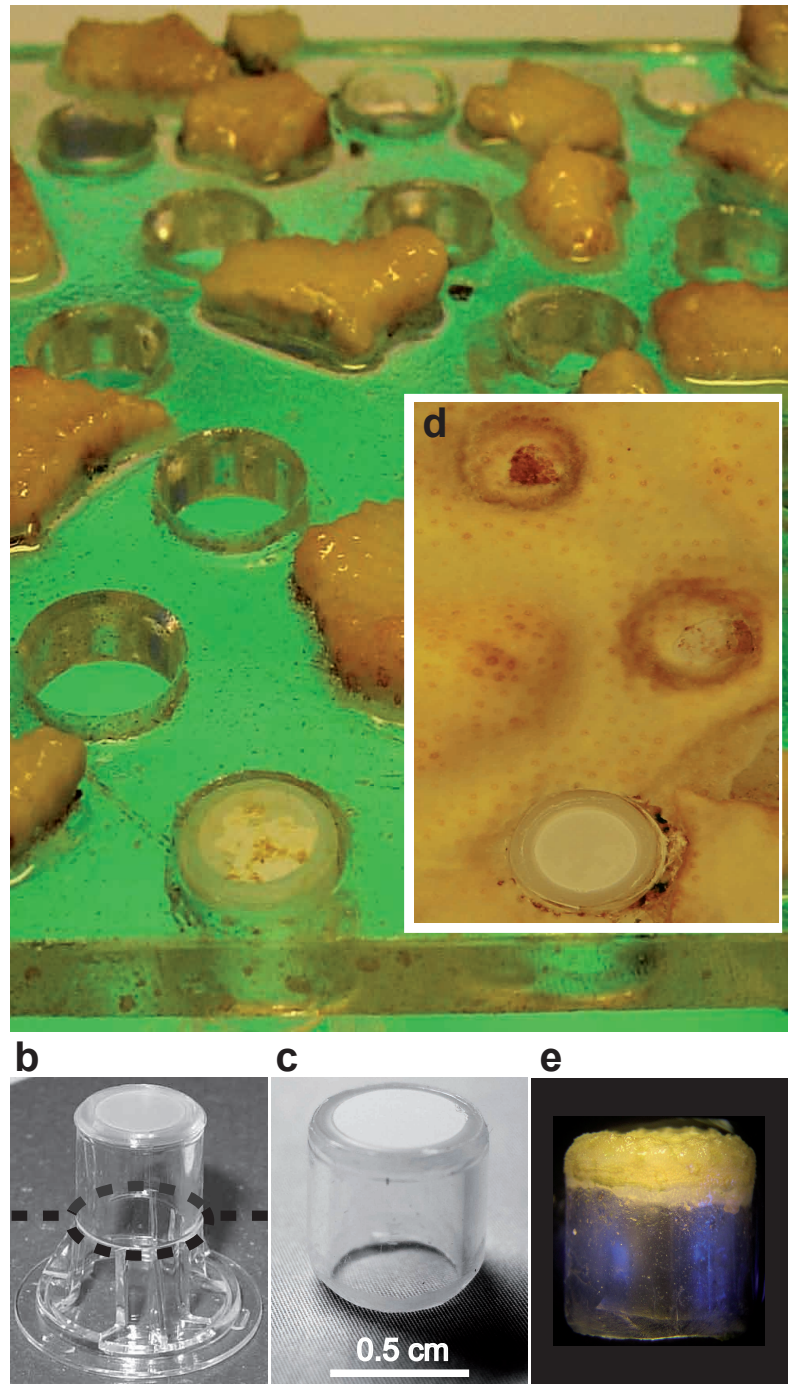




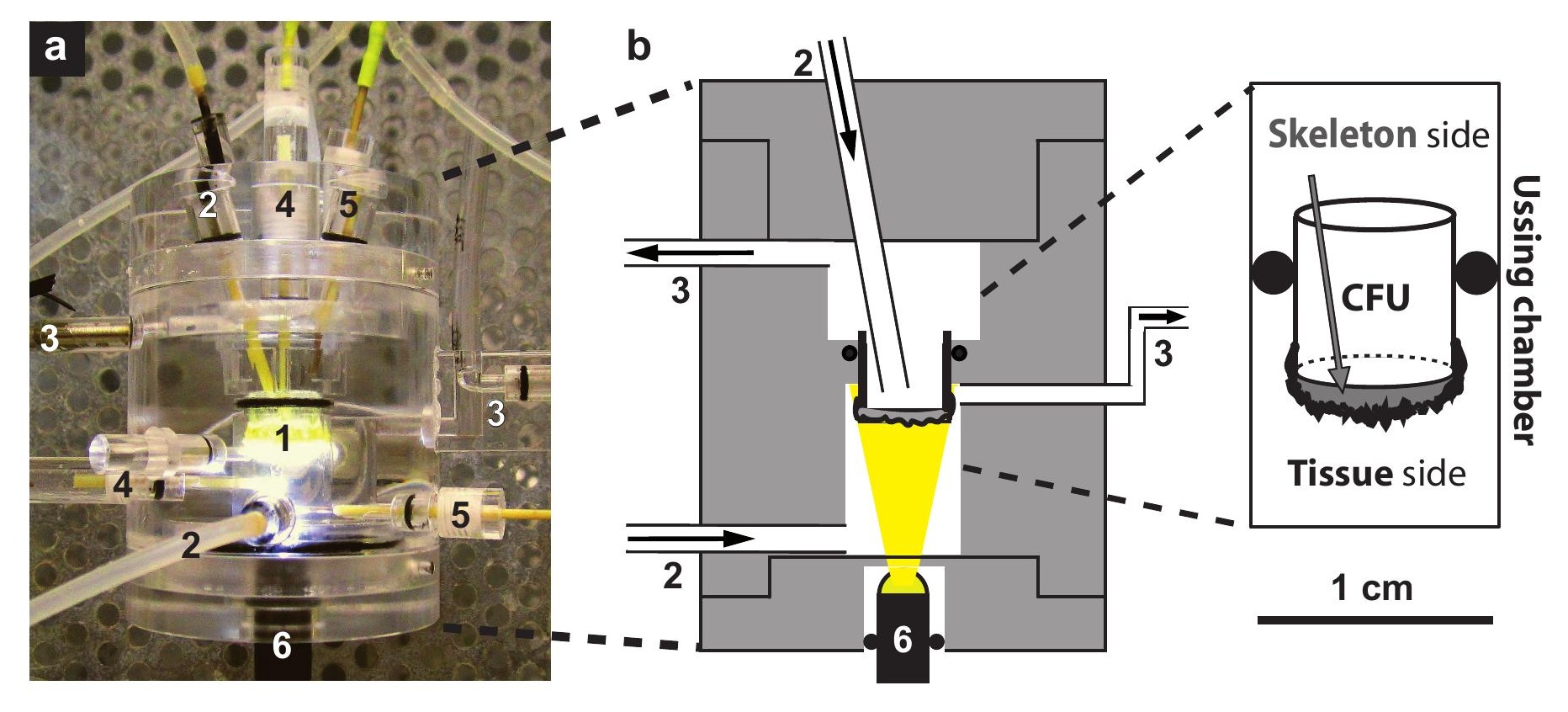

Fig. 3 
Fig. 4
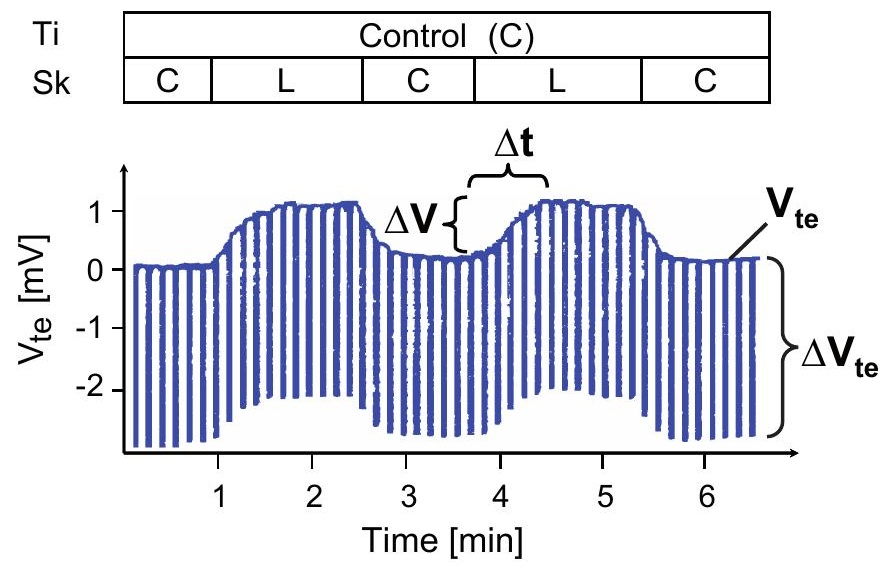
Fig. 5

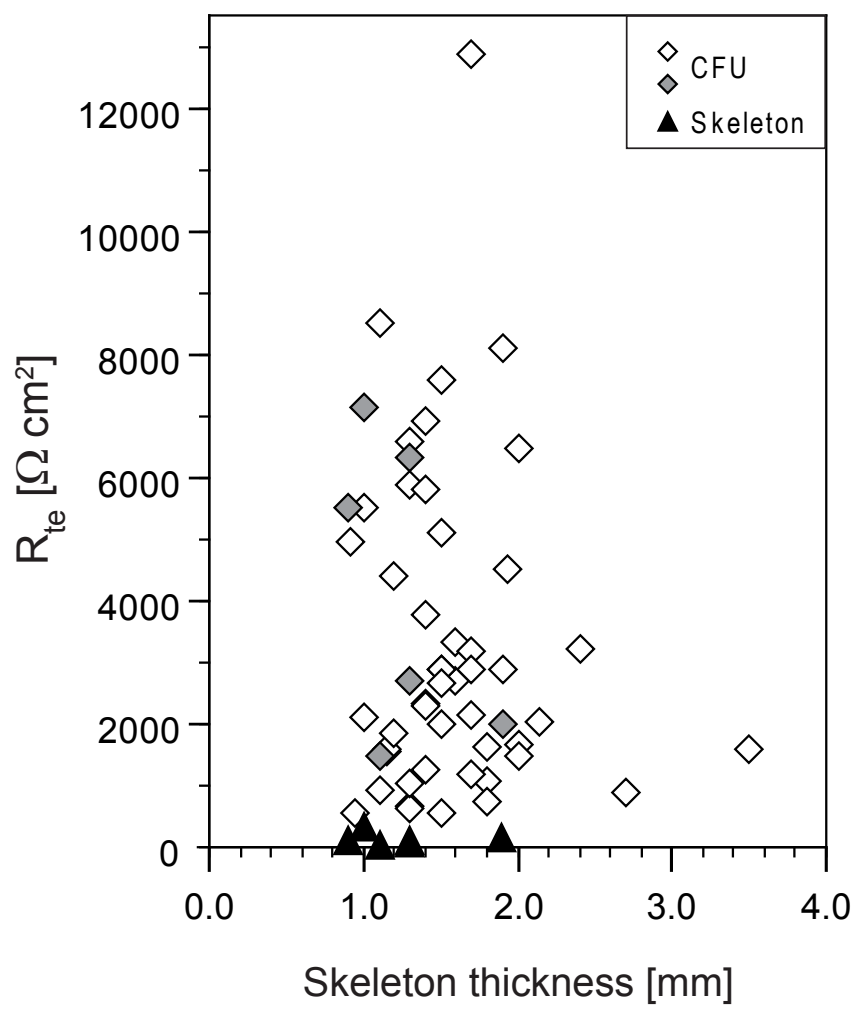


Fig. 6

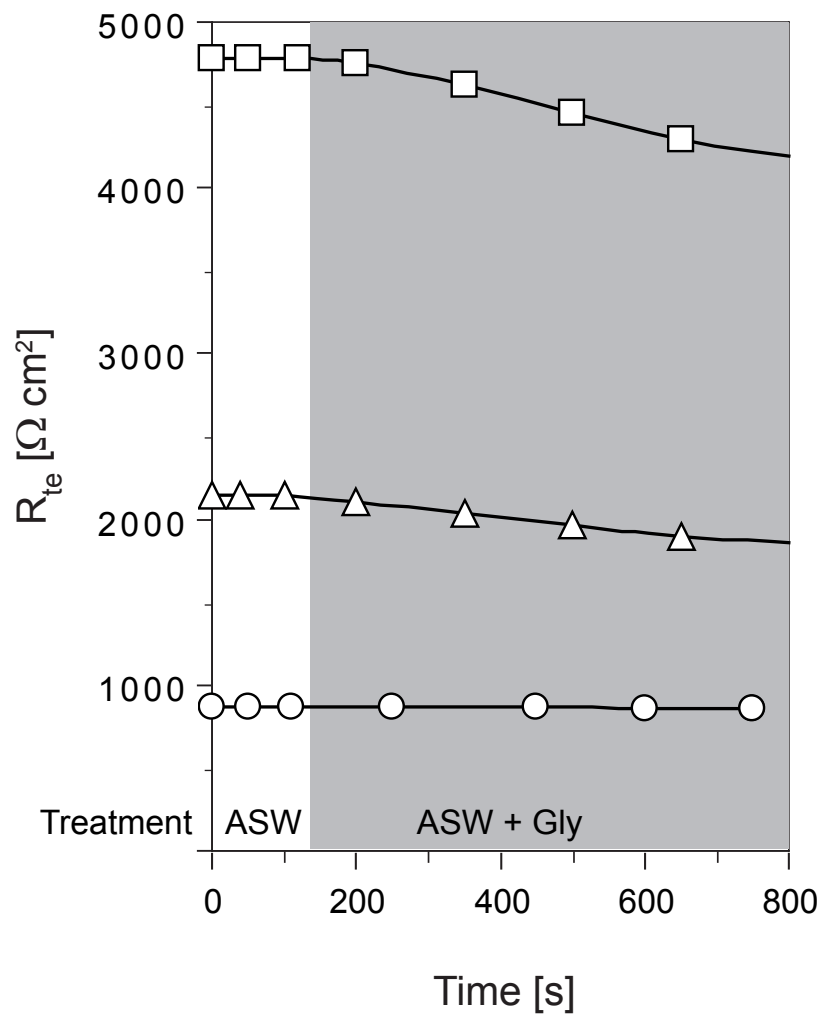


Fig. 7

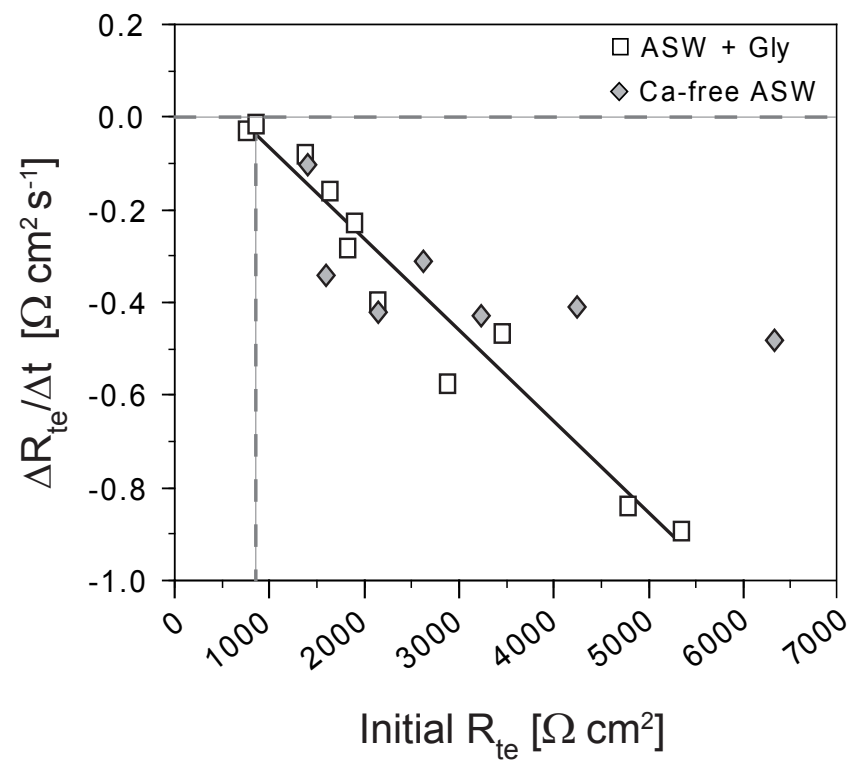


Fig. 8

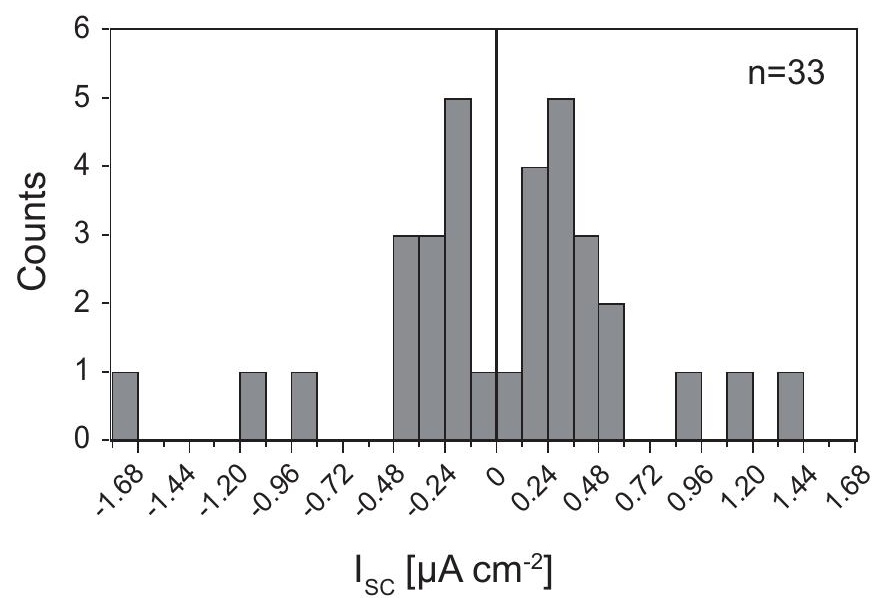


Fig. 9

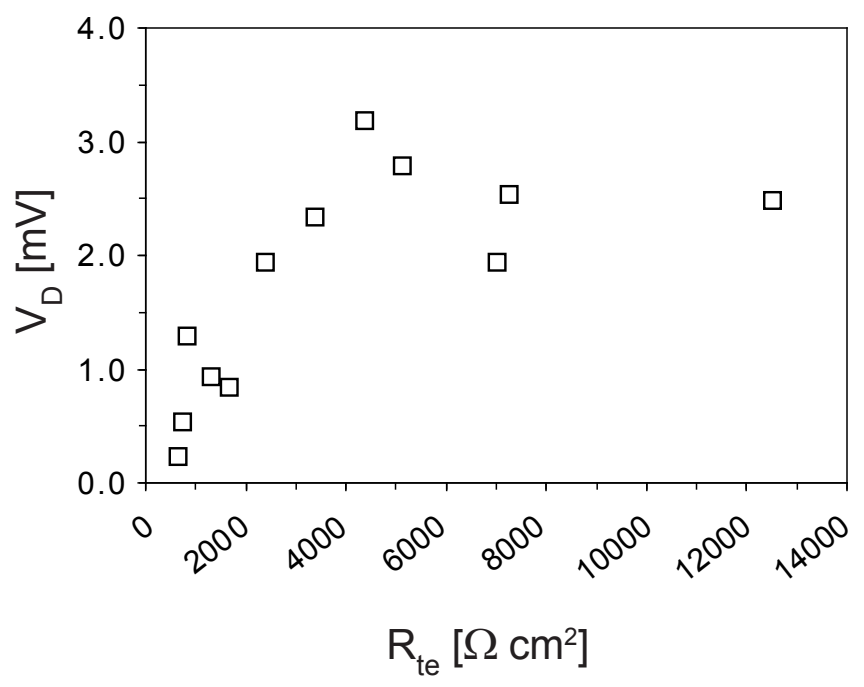




\section{Supplementary information}

\section{Liquid junction potential (LJP)}

The LJP is the sum of the two half-chamber potentials at solution boundaries and calculated with equation S1. Solution boundaries occur at agar bridges of voltage electrodes at each side of the tissue.

$L J P=-\frac{R \times T}{F} \times \frac{\frac{\Sigma_{i}\left(a_{i} 1-a_{i} 2\right) \times u \times\left|z_{i}\right|}{\left|z_{i}\right|}}{\sum_{i}\left(a_{i} 1-a_{i} 2\right) \times u \times\left|z_{i}\right|} \times \frac{\ln \left(\Sigma_{i}\left(a_{i} 1\right) \times u_{i} \times\left|z_{i}\right|\right)}{\sum_{i}\left(a_{i} 1\right) \times u_{i} \times\left|z_{i}\right|}$

$\mathrm{F}$ is the Faraday constant $\left(96485.3 \mathrm{C} \mathrm{mol}^{-1}\right), \mathrm{R}$ is the gas constant $\left(8.31447 \mathrm{~J}^{(\mathrm{mol} \mathrm{K}}\right)^{-}$ 1), $\mathrm{T}$ is the temperature $(298 \mathrm{~K})$; $\mathrm{a}_{\mathrm{i}} 1$ is the ion activity in solution 1 ; $\mathrm{a}_{\mathrm{i}} 2$ is the ion activity in solution 2. Ion activities were calculated using PhreeqC, Version 2.18 (Parkhurst et al. 1999); $u_{i}$ is the mobility of ion $\mathrm{i}$; $\mathrm{z}$ is the valence and $\left|\mathrm{z}_{\mathrm{i}}\right|$ is the absolute value of valence of ion i. Ion mobilities were derived from Barry and Lynch (1991) and Ng and Barry (1995). Perfusing "tissue" and "skeleton" half-chamber with ASW and low NaCl ASW, respectively, we calculated a LJP of $0.47 \mathrm{mV}$. 
Suppl. Tab. 1: Short-term reproducibility of resistance $\left(\mathrm{R}_{\mathrm{te}}\right)$ and potential $\left(\mathrm{V}_{\mathrm{te}}\right)$ of CFUs

\begin{tabular}{|c|c|c|c|c|c|c|c|c|c|}
\hline time [min] ${ }^{a}$ & $\mathbf{0}$ & 30 & 60 & 100 & 180 & 220 & 280 & 340 & 400 \\
\hline CFU \# & \multicolumn{9}{|c|}{$\mathrm{R}_{\mathrm{te}}\left[\Omega \mathrm{cm}^{2}\right]$} \\
\hline 149 & 3300 & 3300 & 3328 & & 3300 & 3328 & 3328 & 3355 & \\
\hline 290 & 3713 & 3754 & 3754 & 3754 & 3713 & & & & \\
\hline 165 & 3960 & 3960 & 3960 & & 4001 & 4001 & 3919 & 3960 & 3960 \\
\hline 272 & 6023 & 5940 & 6023 & & 5940 & & & 6106 & \\
\hline $272^{\mathrm{b}}$ & 7095 & 7095 & & & & 6930 & 6930 & 6930 & \\
\hline 282 & 4950 & 4950 & 4950 & 5033 & & & 5033 & & \\
\hline \multirow[t]{2}{*}{199} & 2160 & & & & 2200 & 2200 & & & 2200 \\
\hline & \multicolumn{9}{|c|}{$\mathrm{V}_{\text {te }}[\mathrm{mV}]$} \\
\hline 149 & -2.3 & -2.4 & -2.3 & & -2.4 & -2.5 & -2.4 & -2.4 & \\
\hline 290 & 1.0 & 1.1 & 1.1 & 1.0 & 1.1 & & & & \\
\hline 165 & 0.7 & 0.7 & 0.8 & & 0.8 & 0.8 & 0.9 & 0.8 & 0.8 \\
\hline 272 & 1.6 & 1.6 & 1.7 & & 1.7 & & & 1.6 & \\
\hline $272^{\mathrm{b}}$ & 0.8 & 0.8 & & & & 0.7 & 0.8 & 0.7 & \\
\hline 282 & 0.6 & 0.7 & 0.6 & 0.6 & & & 0.7 & & \\
\hline 199 & 0.3 & & & & 0.4 & 0.4 & & & 0.3 \\
\hline
\end{tabular}

a time after inserting CFU into Ussing chamber

${ }^{\mathrm{b}}$ second experiment with CFU \#272 was conducted seven days later

Suppl. Tab. 2: Long-term reproducibility of resistance $\left(\mathrm{R}_{\mathrm{te}}\right)$ of CFUs

\begin{tabular}{|c|c|c|c|c|c|c|c|}
\hline time $[d]^{c}$ & $\mathbf{0}$ & 1 & 7 & 20 & 21 & 22 & 121 \\
\hline CFU \# & & & & $\left.\Omega \mathrm{cm}^{2}\right]$ & & & \\
\hline 129 & 5528 & 4488 & & 7128 & 5940 & 5676 & \\
\hline 120 & 7260 & & & & & & 8170 \\
\hline 63 & 4820 & 4880 & & & & & \\
\hline 248 & 4010 & 3000 & & & & & \\
\hline 279 & 3100 & 2750 & & & & & \\
\hline 178 & 7200 & 7100 & 7300 & & & & \\
\hline 395 & 2200 & 1850 & & & & & \\
\hline 272 & 6106 & & 6930 & & & & \\
\hline
\end{tabular}

${ }^{c}$ number of days after first measurement (day 0). Between experiments, CFUs were returned to the culturing aquarium. 
Suppl. Tab. 3: Resistance ( $\left.\mathrm{R}_{\mathrm{te}}\right)$ of skeletons (bleached CFUs) under different treatments

ASWd ASW + Glye

$$
\mathrm{R}_{\mathrm{te}}\left[\Omega \mathrm{cm}^{2}\right]
$$

$325 \quad 330$

$44 \quad 45$

$103 \quad 104$

$123 \quad 125$

$92 \quad 97$

$125 \quad 129$

d ASW = artificial seawater made from single salts

e Glycine was added to ASW to produce iso-saline, but hyper-osmotic seawater. 


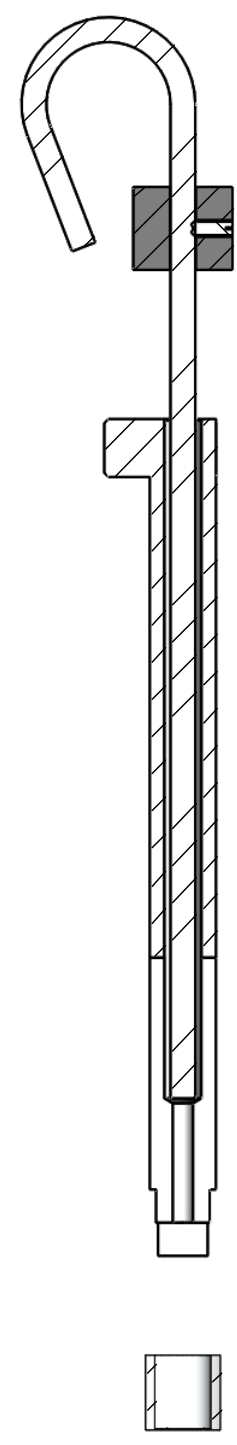

a

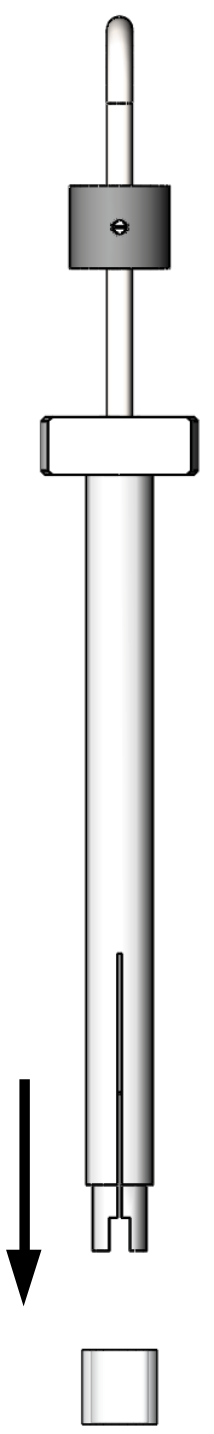

b
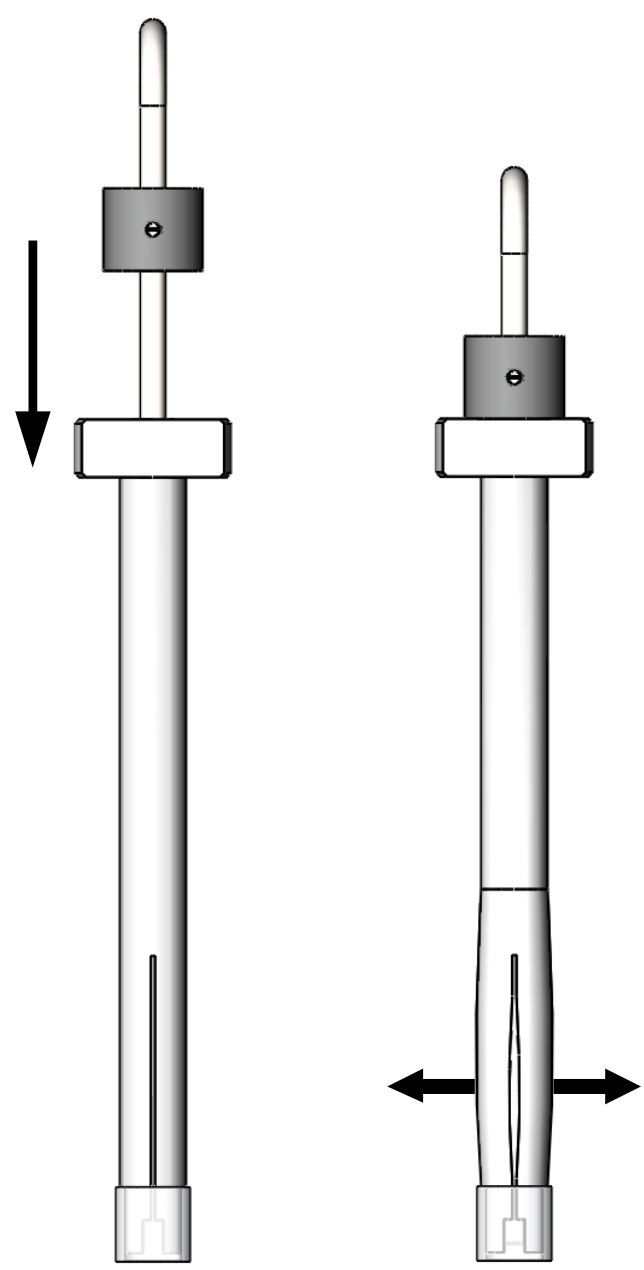

d

Suppl. Fig. 1: Plunger for contact free CFU mounting into Ussing chamber.

Technical drawing (a) and functional scheme (b-d). Cross section of a filter support (bottom) and the plunger consisting of a steel core inserted into teflon shaft (a). Plunger is first inserted into the filter support (b) before the steel core is pushed down (c), causing the Teflon shaft to span tightly inside the filter support (d). 


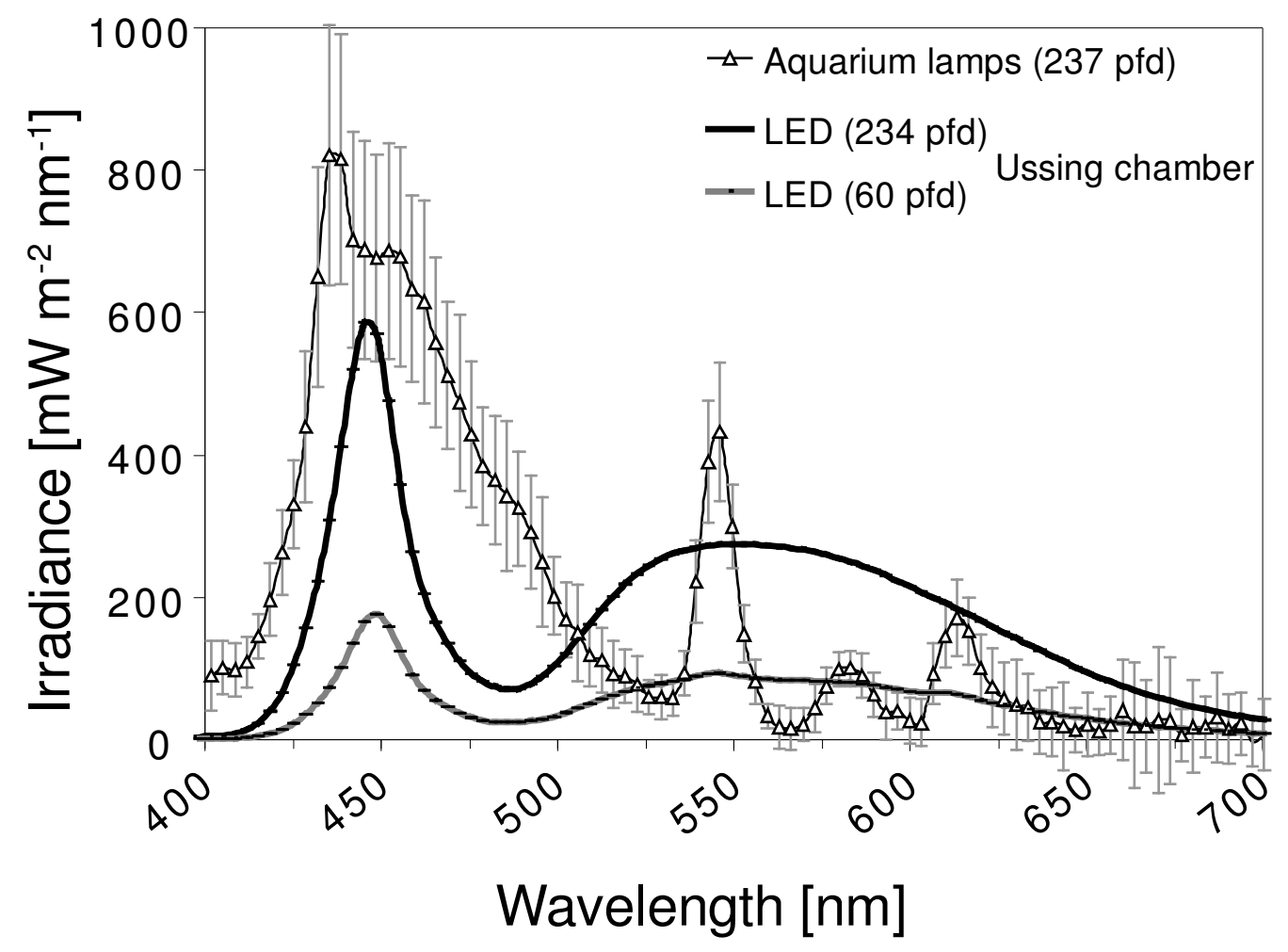

Suppl. Fig. 2: Light spectra and light intensities as pfd (photon flux densities in $\mu$ mol $\mathrm{m}^{-2} \mathrm{~s}^{-1}$ ) at the surface of CFUs in the culturing aquarium and in the Ussing chamber. LED current set to 2 different values. Error bars are $\pm 1 s d, n=6$ for LED and $n=10$ for aquarium.

\section{References}

Barry P.H., Lynch J.W. 1991. Liquid junction potentials and small cell effects in patch-clamp analysis. J. Membr. Biol. 121, 101-117.

Ng B., Barry P.H. 1995. The measurement of ionic conductivities and mobilities of certain less common organic ions needed for junction potential corrections in electrophysiology. J. Neurosci. Meth. 56, 37-41.

Parkhurst D. L., Appelo C. A. J., and U.S.G.S. 1999. User's guide to PHREEQC (version 2) - A computer program for speciation, batch-reaction, one-dimensional transport, and inverse geochemical calculations: Denver, Colorado, U.S. Geological Survey Water-Resources Investigations Report 99-4259, 312 p. 